\title{
Articles
}

\section{The Relationship Between Family Socialization Styles and Ambivalent Sexism in Adolescence}

\author{
Jorge-Manuel Dueñas ${ }^{\star}$, Bernardina Santiago-Larrieuª, Gisela Ferre-Rey ${ }^{a}$, Sandra Cosi ${ }^{a}$
}

[a] Psychology Department, Universitat Rovira i Virgili, Tarragona, Spain.

\begin{abstract}
The aims of the present study are to identify the role that family socialisation styles play in ambivalent sexism and whether differences in sexism can be attributed to gender. We used a sample of 207 adolescents (56.5\% girls), all of whom attended state schools and were aged between 14 and 18 years old, with an average age of $16.2(\mathrm{SD}=1.7)$. The instruments used were the Ambivalent Sexism Inventory (ASI) consisting of two factors - hostile sexism and benevolent sexism - and the Family Socialization Scale (SOC-30) made up of four subscales: support, punishment/coercion, overprotection/control, and reprobation. The results show that boys presented higher levels of ambivalent sexism than girls and the reprobation of adolescents was the family socialization type that had the strongest associations with ambivalent sexism scales in both genders. The data suggest that family socialisation dynamics play an important role in the acquisition and retention of sexist attitudes.
\end{abstract}

Keywords: ambivalent sexism, family socialisation, family reprobation, adolescence

Interpersona, 2020, Vol. 14(1), 28-39, https://doi.org/10.5964/ijpr.v14i1.3923

Received: 2019-11-30. Accepted: 2020-04-24. Published (VoR): 2020-07-02.

*Corresponding author at: Departament de Psicologia, Carretera de Valls s/n. 43007, Tarragona, Spain. Phone: +34 977256183, Fax: +34 977558088, E-mail: jorgemanuel.duenas@urv.cat

This is an open access article distributed under the terms of the Creative Commons Attribution 4.0 International License, CC BY 4.0 (https://creativecommons.org/licenses/by/4.0/), which permits unrestricted use, distribution, and reproduction in any medium, provided the original work is properly cited.

The term "sexism" refers to any positive or negative cognitive, affective or behavioural evaluation of a person based on his or her biological category or gender (Expósito, Moya, \& Glick, 1998). Historically, one of the first contributions to the study of sexism was made by Allport (1979), who defines it as an antipathy to women resulting from the traditional low status given to them. This openly hostile sexism that has traditionally targeted women has continued to increase in recent years and it now embraces other forms of sexism that are more delicate and imperceptible, but just as harmful (Lameiras Fernández \& Rodríguez Castro, 2003; Leaper \& Spears Brown, 2018).

Various theories have been advanced for the study of sexism, one of which is the ambivalent sexism theory (AS; Glick \& Fiske, 1996, 2018). Ambivalent sexism is a two-dimensional construct consisting of two types of sexist attitude: hostile sexism and benevolent sexism. Hostile sexism is the most traditional sexism in terms of its negative emotional charge. It is defined as a prejudice that considers women to be inferior to men in all respects. Men feel superior to women (hostile attitude), and regard themselves to be the bearers of power and responsible for keeping women down. Benevolent sexism emphasises positive emotional aspects, idealising traditional women's roles while accentuating their weakness and need for protection, and reinforcing men's 
complementary role of protector (benevolent attitude; Curun, Taysi, \& Orcan, 2017). The combination of these two types of sexism leads to positive and negative subjective feelings towards both genders and gives rise to ambivalent sexism (Connor, Glick, \& Fiske, 2017; Glick \& Fiske, 2001, 2018; Lameiras Fernández \& Rodríguez Castro, 2003).

Glick and Fiske $(1996,2018)$ described three subfactors for benevolent sexism: a) protective paternalism: the duty that men feel to protect and provide for women, who depend on them; b) complementary gender differentiation: the belief that women indeed have positive characteristics but only in the context of conventional lower status gender roles that are complementary to men's roles; and c) heterosexual intimacy: the belief that romantic heterosexual relationships are essential for men and women to achieve true happiness.

Sexist attitudes, beliefs, and behaviours can be identified in childhood and adolescence (Sagone, De Caroli, Coco, \& Perciavalle, 2018). It seems that sexism can be explained by gender differences at this stage of human development, and various studies on ambivalent sexism in adolescence have suggested that boys are more susceptible to reaching higher levels of sexism (Ferragut, Blanca, Ortiz-Tallo, \& Bendayan, 2017; Malonda, Tur-Porcar, \& Llorca, 2017; Vandenbossche, Spruyt, \& Keppens, 2018). More specifically, the results of a longitudinal study by Ferragut et al. (2017) revealed higher levels of hostile sexism in boys than in girls, with no variation over time. However, benevolent sexism scores decreased equally in both sexes between the ages of 12 and 14 years old. Although most studies show higher levels of benevolent sexism in men than in women, sexist beliefs and behaviours occur in both sexes in adolescence (Leaper \& Spears Brown, 2018). Another study of Mexican adolescents shows that boys scored higher than girls on ambivalent sexism, and girls scored higher than boys on hostile sexism toward women (Nava-Reyes, Rojas-Solís, Greathouse Amador, \& Morales Quintero, 2018). Other studies provide similar data. For example, the study by Löf and Löf (2017) revealed that Swedish teenage boys scored higher on sexism than girls. In addition, boys who had a sister did not have lower levels of sexism. Along the same lines, in Argentine adolescents hostile sexism correlated with stereotypes towards women that they considered to be hostile, while benevolent sexism did not correlate with benevolent stereotypes, probably because teenagers regarded some benevolent stereotypes to be positive and others negative (Etchezahar \& Ungaretti, 2014). This trend extends into adulthood. For example, a study by Cross and Overall (2018) found that women who were more anxious about emotional attachments and the need for safety considered men with benevolent sexist attitudes and behaviours more attractive and preferred partners who had benevolent sexist attitudes. In the Romani people they found that men tended to show more hostile sexism while women had higher scores on benevolent sexism. The social normalisation of benevolent sexism is especially harmful for gender equality because it offers benefits that hide the potential costs of sexist attitudes (Connor et al., 2017; Glick \& Fiske, 1996, 2018).

In the Spanish context, the reported data is similar to that previously reported in other countries. More specifically, recent studies show higher values of hostile and benevolent sexism in boys than in girls (Ferragut et al., 2017; Ramiro-Sánchez, Ramiro, Bermúdez, \& Buela-Casal, 2018). However, other studies find higher levels of benevolent sexism in girls than in boys (Montañés, Megías, de Lemus, \& Moya, 2015), It seems that benevolent sexist attitudes in girls increase with age in different cultures, which may be related to the conception of romantic love present in most cultures.

From a socio-educational perspective, the family is responsible for the core components of informal education, as well as transferring knowledge and strategies to their sons and daughters (Duncan \& Goddard, 2017; 
Osorio, Borrell, Irala, Calatrava, \& López, 2009). An important factor in socialisation processes is that parental socialisation styles should have at least two dimensions: a content aspect (what is transmitted) and a formal aspect (how it is transmitted). The content is the values parents teach to their children, which depend on their own personal values and dominant value system in the extended sociocultural environment. The formal dimension, also known as family discipline, refers to the socialisation mechanisms and strategies used by one or both parents to regulate conduct and transmit cultural content. Therefore, although parents may use some aspects of each of these socialisation styles or adopt different parenting styles in different situations, they tend to have one dominant style that they use more frequently than others, regardless of the sex of their adolescent children (Garaigordobil \& Aliri, 2012; Musitu, 2000).

Some authors have suggested that there is a relationship between family variables, gender perception and emotional factors during adolescence. In particular, a study by lbabe, Elgorriaga, and Arnoso (2017) on a sample of Spanish young adults identified exposure to conjugal violence in childhood as a predictor of ambivalent sexism and psychological damage. However, exposure to marital violence is not a predictor of hostile sexism or benevolent sexism in children. In the same vein, Ibabe (2015) suggests that there is a relationship between a positive family environment and lower levels of violent behaviour by children towards their parents. Apparently, adolescents who attack members of their own family tend to have a negative perception of their family environment and their relationship with their parents. Meanwhile, paternalistic attitudes may influence how the family is understood (ideal family stereotypes) and how adolescents understand occupational identities: for example, jobs traditionally associated with men (the police and mechanics) and traditionally associated with women (nurses and dancers; Farkas \& Leaper, 2016).

Although the influence of the family context on sexism is of fundamental importance, not enough research has focused on the relationship between the sexism of progenitors and their children or in other words, on the inter-generational connection and/or transmission of sexism (Ashraf, 2015; Garaigordobil \& Aliri, 2011). Apparently, this inter-generational transmission can occur by means of family socialization, which refers to the process by which cultural aspects are transmitted from one generation to the next. Therefore, family socialization is an informal educational practice, largely unconscious, by which children and adolescents interactively acquire knowledge, attitudes, values, customs, and ways to express feelings and emotions that characterise the family environment (Duncan \& Goddard, 2017; Musitu, 2000).

Although the relationship between family socialization and ambivalent sexism has been little studied, some researchers point to the importance of parenting styles in the generational transmission of sexist attitudes. For example, Malonda et al. (2017) analysed the correlations of hostile sexism and benevolent sexism with parenting styles in Spanish adolescents and found that permissiveness was related to both types of sexism, while negligence was related only to hostile sexism. From another perspective, a study with young Turks concluded that insecure attachments to the mother were related to interpersonal cognitive distortions, in turn, these interpersonal cognitive distortions were related to higher levels of hostile sexism. Seemingly secure attachments to the mother is a protective factor against sexist attitudes (Bozkur \& Gündoğdu, 2018). A similar study with a Spanish sample, carried out by Garaigordobil and Aliri (2012) found that although fathers showed higher levels of ambivalent sexism, hostile sexism and benevolent sexism than mothers, their educational style had no influence on the level of sexism of their adolescent daughters. However, the mother's educational style had a greater influence than the father's on the level of sexism of the adolescent son and daughter. In addition, a high parental educational level was related to lower levels of sexism in their adolescent children, with the 
mother's educational level having a greater influence on the level of sexism of their daughters. Apparently, there is an intergenerational connection of sexism in the family: from mothers to their sons and daughters and from fathers to sons. The influence of sexism in families on the sexist attitudes of children can be explained by Bandura and Walters' (1964) theory of social learning. According to Bandura (1977), prejudices can be learned from various sources: a) the family, the main source of learning; b) sociocultural sources, that is to say the context in which people develop, and c) symbolic modeling, learning by observing real models, images, stereotypes, words and actions. So the sexist attitudes of adolescents may be related to the type of family.

Considering the lack of studies on the relationship between sexism and family education, the main objectives of this study are to determine the role that family socialization styles play in the ambivalent sexism of adolescents, and to analyse the sex differences in the different types of sexism studied.

Bearing in mind the results of the studies mentioned above, we expect to find significant differences between the different types of sexism, with men having generally higher levels (Ferragut et al., 2017; Malonda et al., 2017; Rojas Pedregosa \& Moreno Díaz, 2016; Vandenbossche et al., 2018) because they have been exposed to social and cultural gender constructions from an early age (Lipowska, Lipowski, Pawlicka, 2016; Ortner \& Whitehead, 1981). We also expect to find meaningful correlations between family socialization and ambivalent sexism in adolescents. Although few previous studies have correlated these two variables, the research on a Spanish population conducted by Garaigordobil and Aliri (2011) revealed that higher levels of sexism in progenitors was related to higher levels of sexism in their children. Lastly, we expect family socialization styles to have different predictive values for the two types of sexism, which points to the possibility of the generational transmission of sexism (Ashraf, 2015; Montañés et al., 2012).

\section{Method}

\section{Participants}

The sample consisted of 207 adolescents (56.5\% women) from two state high schools in the city of Tarragona (Spain). The sampling was non-probabilistic by convenience and the age range of the subjects was from 14 to 18 years old, with an average of $16.2(S D=1.75)$. To access the sample, the research group contacted four high schools. Schools were only contacted if they were not classified as high complexity, the percentage of immigrant students was not above the average for the geographical zone and the students were of a heterogeneous socioeconomic level. Of the four high schools contacted, two agreed to participate in the study.

\section{Measures}

The Inventory of Ambivalent Sexism for Adolescents (ISA; de Lemus, Castillo, Moya, Padilla, \& Ryan, 2008), adapted to Spanish from the Ambivalent Sexism Inventory (ASI; Glick \& Fiske, 1996), consists of 20 items with a five-point response format (1. Completely disagree to 5 . Completely agree). The inventory uses two factors to measure the ambivalent sexism in adolescents: a) hostile sexism (10 items) and b) benevolent sexism (10 items). The instrument also provides an overall ambivalent sexism score. Both the original instrument and Spanish adaptation present suitable psychometric properties. In our sample, we obtained Cronbach alpha coefficients similar to those obtained by the authors (SA, $\alpha=.86 ; \mathrm{HS}, \alpha=.84$; SB, $\alpha=.82$ ). 
The Family Socialization Scale (SOC-30) is a reduced version of the EMBU questionnaire for the Spanish population (Perris, Jacobsson, Linndström, von Knorring, \& Perris, 1980) developed by Herrero, Musitu, García, and Gomis (1991). The instrument contains 30 items and uses a Likert scale with five alternative answers ranging from (1) completely disagree to (5) completely agree. The SOC-30 measures the adolescents' perception of the socialisation style used by their progenitors. The scale has four factors: a) support (11 items), evaluating the active help provided by progenitors and the emotional support received, which is perceived as the expression of affection, comprehension and acceptance; b) punishment/coercion (7 items), which refers to a punitive and coercive type of socialisation, with special emphasis on physical punishment; c) overprotection/control (5 items) represents exaggerated parental concern about the activities of their children, characterised by the adolescents perceiving that they are being controlled and having their autonomy restricted; $d$ ) reprobation (7 items) refers to the non-acceptance of children by the parents, represented by the use of emotional affect as an instrument to influence the behaviour of their children. The original instrument presents adequate psychometric properties. Similar reliabilities to those presented by the authors were obtained with our sample (support, $\alpha$ $=.91$; punishment/coercion, $\alpha=.82$; overprotection/control, $\alpha=.73$; reprobation, $\alpha=.82$ ).

\section{Procedure}

This study followed the guidelines of Spanish Organic Law 15/1999 and the Spanish Agency for Data Protection, which regulate the fundamental right to the protection of data. The first page of the survey explained the objectives of the study and the level of data protection. The students were guaranteed the right to anonymity and to the confidentiality of the results. The questionnaires were administered collectively during school hours, after the institution had given its authorisation and the students had voluntarily agreed to participate. As a participation requirement, parents were asked to give their informed consent. Professional psychologists gave the adolescents instructions on how to answer the tests and helped them during the session.

\section{Data Analysis}

The normality of the data was analysed using the Kolmogorov-Smirnov test. As we found that some measures (family socialization of support and family socialization of punishment/coercion) were not normally distributed throughout the sample $(p<.05)$, we performed non-parametric analyses when these variables were involved. The Mann-Whitney $U$ test (in non-normally distributed variables) and the $t$-test (in normally distributed variables) were used to examine sex differences in ambivalent sexism and family socialization. In both cases Cohen's $d$ was used to obtain the effect size, categorized according to these criteria: $0.2<d<0.5=$ small, 0.5 $<d<0.8=$ medium; and $d>0.8=$ large (Cohen, 1988). In addition, the degree of association between scales of family socialization and scales of ambivalent sexism in the sample separated by sex was analysed using Spearman's correlation test. To interpret the strength of the correlation we used the classifications proposed by Guilford (1956). All the analyses were performed using the Statistical Package SPSS 25.0, at a significance level of .05.

\section{Results}

Table 1 shows sex differences in different types of sexism and in the family socialization subscales. On the one hand, as expected, men obtained higher scores on all subscales and a higher total score of ambivalent 
sexism than women (hostile sexism: $t_{166}=-5.88, p<.001$, benevolent sexism: $t_{205}=-2.52, p<.05$, ambivalent sexism: $t_{205}=-4.85, p<.001$ ). According to Cohen's (1988) classification, the effect size is large for hostile sexism, medium for ambivalent sexism, and small for benevolent sexism. Specifically, men averaged nearly nine points more than women for hostile sexism (difference $=8.92, p<.01, d=0.85$ ), and even more for ambivalent sexism (difference $=16.42, p<.01$ ), although the effect size is more moderate $(d=0.68)$. Lastly, the effect size was small for benevolent sexism (difference $=10.19, p<.01, d=0.35$ ) and benevolent sexism subfactors: protective paternalism (difference $=6.40, p<.01, d=0.37$ ) and heterosexual intimacy (difference = $3.57, p<.01, d=0.35)$. On the other hand, there were no sex differences in any family socialization scales.

Table 1

Sex Differences in Ambivalent Sexism and Family Socialization

\begin{tabular}{|c|c|c|c|c|c|c|c|}
\hline \multirow[b]{2}{*}{ Variable } & \multicolumn{2}{|c|}{ Boys $(n=90)$} & \multicolumn{2}{|c|}{ Girls $(n=117)$} & \multirow[b]{2}{*}{$t / Z$} & \multirow[b]{2}{*}{$p$} & \multirow[b]{2}{*}{$d$} \\
\hline & $M$ & $S D$ & $M$ & $S D$ & & & \\
\hline HS & 29.29 & 10.02 & 21.72 & 7.97 & 5.88 & $<.001$ & 0.85 \\
\hline BS & 31.28 & 10.17 & 27.68 & 10.21 & 2.52 & $<.05$ & 0.35 \\
\hline PP & 16.78 & 6.52 & 14.38 & 6.31 & 2.65 & $<.01$ & 0.37 \\
\hline CG & 5.91 & 2.56 & 5.96 & 2.47 & -0.13 & n.s. & - \\
\hline $\mathrm{HI}$ & 8.59 & 3.71 & 7.33 & 3.46 & 2.51 & $<.05$ & 0.35 \\
\hline AS & 60.57 & 16.70 & 49.39 & 16.20 & 4.85 & $<.001$ & 0.68 \\
\hline FS of support & 24.60 & 8.92 & 24.19 & 9.27 & 0.54 & n.s. & - \\
\hline FS of punishment/coercion & 11.45 & 4.85 & 10.88 & 4.32 & 0.58 & n.s. & - \\
\hline FS of overprotection/control & 16.64 & 3.97 & 16.88 & 3.86 & -0.43 & n.s. & - \\
\hline FS of reprobation & 16.63 & 4.22 & 16.19 & 4.77 & 0.70 & n.s. & - \\
\hline
\end{tabular}

Note. HS = Hostile Sexism; BS = Benevolent Sexism; PP = Protective Paternalism; CG = Complementary Gender differentiation; HI =

Heterosexual Intimacy; AS = Ambivalent Sexism; FS = Family Socialization; n.s. = non significant.

Table 2 shows the Spearman correlations between the SOC-30 subscales and the different types of sexism for the general sample. Reprobation was related positively with all ambivalent sexism scales. It was the family socialization scale with strongest correlations and the lowest association with hostile sexism, ambivalent sexism and benevolent sexism subfactors (protective paternalism, complementary gender differentiation and heterosexual intimacy). The association with benevolent sexism was moderate. Furthermore, support was positively associated with benevolent sexism, and punishment/coercion was positively related with benevolent sexism and heterosexual intimacy, although both with very low intensity.

Table 2

Spearman Correlations Between the Different Types of Sexism and the Family Socialization Subscale in the Whole Sample

\begin{tabular}{lllllll}
\hline Variable & HS & BS & AS & PP & CG & HI \\
\hline FS of support & $.15^{\star}$ & -.07 & .06 & -.11 & -.03 & .02 \\
FS of punishment/coercion & .07 & $.15^{\star}$ & .13 & .10 & .08 & $.18^{\star}$ \\
FS of overprotection/control & .05 & .09 & .07 & .10 & .05 & .08 \\
FS of reprobation & $.20^{\star *}$ & $.41^{* * *}$ & $.35^{\star * *}$ & $.35^{\star * *}$ & $.26^{\star \star *}$ & $.33^{\star * *}$ \\
\hline
\end{tabular}

Note. HS = Hostile Sexism; BS = Benevolent Sexism; PP = Protective Paternalism; CG = Complementary Gender differentiation; HI = Heterosexual Intimacy; AS = Ambivalent Sexism; FS = Family Socialization.

${ }^{*} p<.05 .{ }^{* *} p<.01 .{ }^{* * *} p<.001$. 
We calculated the same correlations after we had separated the sample by sex and we found only slight differences between the two matrix correlations: the correlation between the support and hostile sexism, as well as between punishment/coercion and heterosexual intimacy just reached significance in the men's subsample ( $r=.24, p<.05, r=.22, p<.05$, respectively). The same occurs between reprobation and hostile sexism, where only the women present a slight significant association $(r=.23, p<.05)$.

\section{Discussion}

One of the aims of this study was to analyse the differences in ambivalent sexism scores between adolescent women and men. Our results show sex differences in hostile sexism, benevolent sexism and ambivalent sexism scores. These differences were significantly higher in men, with a medium-large effect size for hostile sexism and ambivalent sexism and a lower effect size for benevolent sexism. This data is coherent with that reported in previous studies with adolescent samples (Ferragut et al., 2017; Garaigordobil, 2015; Malonda et al., 2017; Ramiro-Sánchez et al., 2018; Vandenbossche et al., 2018).

The main purpose of this study was to determine the role that the family socialization style plays in ambivalent sexism in adolescents. Our results show that reprobation is the family socialization type that has the strongest association with all ambivalent sexism scales. Therefore, adolescents whose parents use emotional affect to influence their behaviour are more disposed to manifest sexist attitudes of the ambivalent type, whether these be hostile or, especially, benevolent. The relation between family socialization and ambivalent sexism has been little studied. However, previous research has indicated that there is a relationship between psychological parental control and the different types of sexism. Specifically, Malonda et al. (2017) suggest that sexism is associated with psychological parental control, so a family environment of emotional and psychological reprobation can promote hostile and benevolent sexist attitudes through diverse family dynamics. In fact, Bermúdez, Sharp, and Taniguchi (2015) suggest that traditional family gender roles can explain hostile sexism and benevolent sexism because gender roles are a social construct that have their origin in the most immediate social unit: the family (Gaunt \& Pinho, 2018; Montañés et al., 2012).

We also analyse the relationship between the three subfactors of benevolent sexism (protective paternalism, complementary gender differentiation and heterosexual intimacy) and family socialization styles. The data suggest that the family socialization style of reprobation is related to all three subfactors. This is something that few previous studies have done. Our data is consistent with the literature. More specifically, the study by Farkas and Leaper (2016) reports a relationship between paternalism and the selection of occupational options. In turn, some studies report an association between occupational choices and family roles, family support and family expectations (Akosah-Twumasi, Emeto, Lindsay, Tsey, \& Malau-Aduli, 2018; Fouad, Kim, Ghosh, Chang, \& Figueiredo, 2016; Hui \& Lent, 2018). So these variables are expected to be related. On the other hand, some studies suggest that gender stereotypes are sustained under all the different social dynamics, including the family (Dunlap, Barth, \& Chappetta, 2019). It seems that families that use constant disapproval with their children tend to establish traditional gender stereotypes. However, more studies are needed to clarify this relationship. Finally, heterosexual intimacy is the belief that heteronormative and romantic relationships are the path to happiness. Our data suggest that adolescents who are involved in family socialization styles of reprobation tend to have higher scores on heterosexual intimacy. We do not know if any studies have evaluated 
the relationship between these constructs, so empirical approaches need to be used that help to establish the relationship.

In summary, this study examined the influence of family socialisation on the propagation of ambivalent sexist attitudes in adolescents. In particular, it has found that the family socialization factor of reprobation is a variable that contributes to ambivalent sexism in adolescents, especially benevolent sexism. However, the other family socialization factors of support, punishment/coercion and overprotection/control do not seem to explain the additional variability that reprobation accounts for. The results of the present study reveal the possible influence of family socialization styles on the construction of sexist tendencies in adolescents. Nevertheless, further longitudinal and sequential studies must be performed to obtain a more extensive perspective of the relationship between these variables and to determine their evolution during the course of adolescence and the transition to adulthood. Research is needed to analyse the levels of ambivalent sexism in both parents and children and the effectiveness of sexism prevention and intervention programs.

\section{Practical Implications}

The results of the present investigation have various educational implications for both educational psychologists and educational counsellors. Our data suggest that there is a relationship between some styles of family socialization and ambivalent sexism, especially benevolent sexism and its subfactors. Benevolent sexism is just as detrimental to gender equality as hostile sexism because, being based on traditional gender stereotypes, it harms men, women and people who are not binary. This type of sexism masks a social prejudice. Accepted as a standard social dynamic, it excludes men and women who do not fit the stereotype. Our results may be of interest for organizing psychoeducational programs to prevent sexism in adolescents. And more specifically, they may be used to design and develop group counselling initiatives (Konstadinidis \& Goga, 2015) so that parents can be informed, guided and trained (Epstein et al., 2018). If trainers at parent schools were able to detect the variables that explain benevolent sexism, they would have tools to create more effective training courses.

Various intervention programs have proved to be effective at reducing sexism levels in Spanish adolescents (Carrascosa, Cava, Buelga, \& de Jesus, 2019; Navarro-Pérez, Carbonell, \& Oliver, 2019). Most of these programs have several characteristics in common: a) they had at least 11 hours of training b) they were taught by specialized professionals, c) they used gamification and role-play and, d) sexism was related to romantic myths. Although these programs proved to be effective and valid in the Spanish context, the programs were only for adolescents not parents and families. In the light of our results, programs for the prevention of sexism and the promotion of gender equality should include families if they are to have an impact, bearing in mind that the sexist attitudes of parents can influence adolescent sexism (Bozkur \& Gündoğdu, 2018; Malonda et al., 2017). More empirical and longitudinal studies are needed. These studies should analyze sexism prevention programs that involve the families of adolescents.

\section{Funding}

The authors have no funding to report.

\section{Competing Interests}

The authors have declared that no competing interests exist. 


\section{Acknowledgments}

The authors have no support to report.

\section{References}

Akosah-Twumasi, P., Emeto, T. I., Lindsay, D., Tsey, K., \& Malau-Aduli, B. S. (2018). A systematic review of factors that influence youths career choices-the role of culture. Frontiers in Education, 3(58), Article 58. https://doi.org/10.3389/feduc.2018.00058

Allport, G. W. (1979). The nature of prejudice. Boston, MA, USA: Addison-Wesley.

Ashraf, M. (2015). Parental sexism and its relationship with daughters' sexism, self-esteem, and career aspirations [Doctoral dissertation, University of Auckland, Auckland, New Zealand]. Retrieved from https://researchspace.auckland.ac.nz/handle/2292/24397

Bandura, A. (1977). Social learning theory. Upper Saddle River, NJ, USA: Prentice-Hall.

Bandura, A., \& Walters, R. H. (1964). Social learning and personality development. New York, NY, USA: Holt, Rinehart and Winston.

Bermúdez, J. M., Sharp, E. A., \& Taniguchi, N. (2015). Tapping into the complexity. Journal of Family Issues, 36(10), 1274-1295. https://doi.org/10.1177/0192513X13506706

Bozkur, B., \& Gündoğdu, M. (2018). Ambivalent sexism and bonding mother as predictors of interpersonal cognitive distortions. Egitim ve Ögretim, 8(4), 665-680. https://doi.org/10.14527/pegegog.2018.026

Carrascosa, L., Cava, M. J., Buelga, S., \& de Jesus, S. N. (2019). Reduction of sexist attitudes, romantic myths, and aggressive behaviors in adolescents: Efficacy of the DARSI program. Psicothema, 31(2), 121-127. https://doi.org/10.7334/psicothema2018.245

Cohen, J. (1988). Statistical power analysis for the behavioral sciences (2nd ed.). New York, NY, USA: Lawrence Erlbaum Associates. Retrieved from http://www.utstat.toronto.edu/ brunner/oldclass/378f16/readings/CohenPower.pdf

Connor, R. A., Glick, P., \& Fiske, S. T. (2017). Ambivalent sexism in the twenty-first century. In C. G. Sibley \& F. K. Barlow (Eds.), The Cambridge handbook of the psychology of prejudice (pp. 295-320). Cambridge, United Kingdom: Cambridge University Press. https://doi.org/https://doi.org/10.1017/9781316161579.013

Cross, E. J., \& Overall, N. C. (2018). Women's attraction to benevolent sexism: Needing relationship security predicts greater attraction to men who endorse benevolent sexism. European Journal of Social Psychology, 48(3), 336-347. https://doi.org/10.1002/ejsp.2334

Curun, F., Taysi, E., \& Orcan, F. (2017). Ambivalent sexism as a mediator for sex role orientation and gender stereotypes in romantic relationships: A study in Turkey. Interpersona, 11(1), 55-69. https://doi.org/10.5964/ijpr.v11i1.229

de Lemus, S., Castillo, M., Moya, M., Padilla, J. L., \& Ryan, E. (2008). Elaboración y validación del inventario de sexismo ambivalente para adolescentes [Elaboration and validation of ambivalent sexism Inventory for adolescents]. International Journal of Clinical and Health Psychology, 8(2), 537-562. 
Duncan, S. F., \& Goddard, H. W. (2017). Family life education: Principles and practices for effective outreach. Washington, DC, USA: SAGE Publications.

Dunlap, S. T., Barth, J. M., \& Chappetta, K. (2019). Gender roles in the romantic relationships of women in STEM and female-dominated majors: A study of heterosexual couples. Gender Issues, 36(2), 113-135. https://doi.org/10.1007/s12147-018-9223-3

Epstein, J. L., Sanders, M. G., Sheldon, S. B., Simon, B. S., Salinas, K. C., \& Natalie Rodriguez Jansorn, N. ... Kenyatta J. W. (2018). School, family, and community partnerships: Your handbook for action. Newbury Park, CA, USA: Sage.

Etchezahar, E., \& Ungaretti, J. (2014). Woman stereotypes and ambivalent sexism in a sample of adolescents from Buenos Aires. Journal of Behavior, Health \& Social Issues, 6(1), 87-94. https://doi.org/10.5460/jbhsi.v6.2.41328

Expósito, F., Moya, M. C., \& Glick, P. (1998). Sexismo ambivalente: Medición y correlatos [Ambivalent sexism: Measurement and correlates]. Revista de Psicología Social, 13(2), 159-169. https://doi.org/10.1174/021347498760350641

Farkas, T., \& Leaper, C. (2016). Chivalry's double-edged sword: How girls' and boys' paternalistic attitudes relate to their possible family and work selves. Sex Roles, 74(5-6), 220-230. https://doi.org/10.1007/s11199-015-0556-z

Ferragut, M., Blanca, M. J., Ortiz-Tallo, M., \& Bendayan, R. (2017). Sexist attitudes and beliefs during adolescence: A longitudinal study of gender differences. European Journal of Developmental Psychology, 14(1), 32-43. https://doi.org/10.1080/17405629.2016.1144508

Fouad, N. A., Kim, S. Y., Ghosh, A., Chang, W. H., \& Figueiredo, C. (2016). Family influence on career decision making: Validation in India and the United States. Journal of Career Assessment, 24(1), 197-212. https://doi.org/10.1177/1069072714565782

Garaigordobil, M. (2015). Sexismo y expresión de la ira: Diferencias de género, cambios con la edad y correlaciones entre ambos constructos [Sexism and expression of anger: Gender differences, changes with age and correlations between both constructs]. Revista Argentina de Clínica Psicológica, 24(1), 35-42.

Garaigordobil, M., \& Aliri, J. (2011). Conexión intergeneracional del sexismo: Influencia de variables familiares [Intergenerational connection of sexism: Influence of family variables]. Psicothema, 23(3), 382-387.

Garaigordobil, M., \& Aliri, J. (2012). Parental socialization styles, parents' educational level, and sexist attitudes in adolescence. The Spanish Journal of Psychology, 15(2), 592-603. https://doi.org/10.5209/rev_SJOP.2012.v15.n2.38870

Gaunt, R., \& Pinho, M. (2018). Do sexist mothers change more diapers? Ambivalent sexism, maternal gatekeeping, and the division of childcare. Sex Roles, 79(3-4), 176-189. https://doi.org/10.1007/s11199-017-0864-6

Glick, P., \& Fiske, S. T. (1996). The ambivalent sexism inventory: Differentiating hostile and benevolent sexism. Journal of Personality and Social Psychology, 70(3), 491-512. https://doi.org/10.1037/0022-3514.70.3.491

Glick, P., \& Fiske, S. T. (2001). An ambivalent alliance: Hostile and benevolent sexism as complementary jutifications for gender inequality. The American Psychologist, 56(2), 109-118. https://doi.org/10.1037/0003-066X.56.2.109

Glick, P., \& Fiske, S. T. (2018). The ambivalent sexism inventory: Differentiating hostile and benevolent sexism. In S. T. Fiske (ed.), Social Cognition (pp. 116-160). Abingdon, United Kingdom: Routledge. 
Guilford, J. P. (1956). Fundamental statistics in psychology and education (3rd ed). New York, NY, USA: McGraw-Hill.

Herrero, J., Musitu, G., García, F., \& Gomis, M. (1991). Las prácticas educativas de los padres en la adolescencia. In Actas del III Congreso Nacional de Psicología social (Vol 1, pp. 352-361).

Hui, K., \& Lent, R. W. (2018). The roles of family, culture, and social cognitive variables in the career interests and goals of asian american college students. Journal of Counseling Psychology, 65(1), 98-109. https://doi.org/10.1037/cou0000235

Ibabe, I. (2015). Predictores familiares de la violencia filio-parental: El papel de la disciplina familiar [Family predictors of child-to-parent violence: The role of family discipline]. Anales de Psicología, 31(2), 615-625. https://doi.org/10.6018/analesps.31.2.174701

Ibabe, I., Elgorriaga, E., \& Arnoso, A. (2017). The role of violence between parents on the sexism and well-being of their children. Estudios de Psicología, 38(1), 258-268. https://doi.org/10.1080/02109395.2016.1268391

Konstadinidis, L., \& Goga, P. (2015). Parent schools: Definition, progress and structure. PSYCHIATRIKI, 26(2), $141-150$. http://www.psychiatriki-journal.gr/index.php?option=com_content\&view=article\&id=1230\&ltemid=\&lang=en

Lameiras Fernández, M., \& Rodríguez Castro, Y. (2003). Evaluación del sexismo ambivalente en estudiantes gallegos/as [Assessment of ambivalent sexism in Galician students]. Revista Acción Psicológica, 2(2), 131-136. https://doi.org/10.5944/ap.2.2.526

Leaper, C., \& Spears Brown, C. (2018). Sexism in childhood and adolescence: Recent trends and advances in research. Child Development Perspectives, 12(1), 10-15. https://doi.org/10.1111/cdep.12247

Lipowska, M., Lipowski, M., \& Pawlicka, P. (2016). Daughter and son: A completely different story"? Gender as a moderator of the relationship between sexism and parental attitudes. Health Psychology Report, 4(3), 224-236.

https://doi.org/10.5114/hpr.2016.62221

Löf, E., \& Löf, M. (2017). The relations between gender roles, sibling constellations, and modern sexism [Bachelor's thesis, Örebro University, Örebro, Sweden]. Retrieved from http://urn.kb.se/resolve?urn=urn:nbn:se:oru:diva-65469

Malonda, E., Tur-Porcar, A., \& Llorca, A. (2017). Sexism in adolescence: Parenting styles, division of housework, prosocial behaviour and aggressive behaviour [Sexismo en la adolescencia: Estilos de crianza, división de tareas domésticas, conducta prosocial y agresividad]. Revista de Psicología Social, 32(2), 333-361.

https://doi.org/10.1080/02134748.2017.1291745

Montañés, P., de Lemus, S., Bohner, G., Megías, J. L., Moya, M., \& Garcia-Retamero, R. (2012). Intergenerational transmission of benevolent sexism from mothers to daughters and its relation to daughters' academic performance and goals. Sex Roles, 66(7-8), 468-478. https://doi.org/10.1007/s11199-011-0116-0

Montañés, P., Megías, J. L., de Lemus, S., \& Moya, M. (2015). Influence of early romantic relationships on adolescents' sexism [Sexismo en la adolescencia: Influencia de las primeras relaciones de pareja]. Revista de Psicología Social, 30(2), 219-240. https://doi.org/10.1080/21711976.2015.1016756

Musitu, G. (2000). Socialización familiar y valores en el adolescente : un análisis intercultural [Family socialization and values in adolescents: An intercultural analysis]. Anuario de Psicología, 31(2), 15-32. 
Nava-Reyes, M. A., Rojas-Solís, J. L., Greathouse Amador, L. M., \& Morales Quintero, L. A. (2018). Gender roles, sexism and myths of romantic love in mexican adolescents. Interamerican Journal of Psychology, 52(1), $102-111$. https://doi.org/10.30849/rip/ijp.v52i1.341

Navarro-Pérez, J. J., Carbonell, Á., \& Oliver, A. (2019). The effectiveness of a psycho-educational app to reduce sexist attitudes among adolescents. Revista de Psicodidáctica, 24(1), 9-16. https://doi.org/10.1016/j.psicod.2018.07.002

Ortner, S., \& Whitehead, H. (1981). Sexual meanings: The cultural construction of gender and sexuality. Cambridge, United Kingdom: Cambridge University Press.

Osorio, A., Borrell, S. R., Irala, J., Calatrava, M., \& López, C. (2009). Evaluacion de los estilos educativos parentales en una muestra de estudiantes Filipinos: Implicaciones educativas [Assessing parenting styles in a sample of Filipino students: Educational implications]. Revista Panamericana de Pedagogia, 14, 13-37.

Perris, C., Jacobsson, L., Linndström, H., von Knorring, L., \& Perris, H. (1980). Development of a new inventory for assessing memories of parental rearing behaviour. Acta Psychiatrica Scandinavica, 61(4), 265-274. https://doi.org/10.1111/j.1600-0447.1980.tb00581.x

Ramiro-Sánchez, T., Ramiro, M. T., Bermúdez, M. P., \& Buela-Casal, G. (2018). Sexism and sexual risk behavior in adolescents: Gender differences. International Journal of Clinical and Health Psychology, 18(3), 245-253. https://doi.org/10.1016/j.ijchp.2018.04.002

Rojas Pedregosa, P., \& Moreno Díaz, R. (2016). Sexismo hostil y benevolente en adolescentes. Una aproximación étnicocultural. Revista Iberoamericana de Educación, 72(1), 31-46. https://doi.org/10.35362/rie72126

Sagone, E., De Caroli, M. E., Coco, R. F. M., \& Perciavalle, V. (2018). Flexibility of gender stereotypes: Italian study on comparative gender-consistent and gender-inconsistent information. Psicologia dell'Educazione, 24(2), 93-98. https://doi.org/10.5093/psed2018a14

Vandenbossche, L., Spruyt, B., \& Keppens, G. (2018). Young, innocent and sexist? Social differences in benevolent and hostile sexist attitudes towards women amongst Flemish adolescents. Young, 26(1), 51-69.

https://doi.org/10.1177/1103308817697240 